\title{
Analysis of dewatering and desaturation of generic field deposition scenarios for thickened tailings
}

\author{
S Qi Carleton University, Canada \\ P Simms Carleton University, Canada
}

\begin{abstract}
Models that compute dewatering using accurate coupling of evaporation, unsaturated flow and large strain consolidation may have utility in providing guidance to optimise deposition of thickened tailings. A recently developed research model, UNSATCON, is used to analyse some typical field deposition profiles for both hard rock and oil sands fine tailings deposits. Model parameters are selected from previous studies on hard rock and oil sands tailings. Some validation with select field data is presented. Exploratory analysis reveals a number of interesting findings. For hard rock tailings, where self-weight consolidation after lift placement occurs relatively quickly due to high hydraulic conductivity of the tailings, maximisation of density can be achieved for a wide range of lift thickness and rates of rise even with relatively low rates of evaporation. For desaturation and risk of oxidation, lift thickness and deposition timing become more important. For oil sands tailings, the timing of deposition and lift thickness are more important for maximising density due to the much lower hydraulic conductivity and, therefore, the longer time of self-weight consolidation.
\end{abstract}

Keywords: consolidation, unsaturated flow, field deposition, density, saturation, oxidation

\section{Introduction}

Density, strength, and risk of oxidation in a thickened tailings operation can be somewhat controlled by managing deposition in a tailings disposal area. Where the climate allows, evaporation may be used to accelerate dewatering through cycling deposition from different points in the impoundment. For relatively fine grained tailings with slow consolidation, evaporation may help increase rates of rise to achieve necessary densities, while desiccated tailings can be stronger than undesiccated tailings at the same density (Daliri et al. 2016, 2014). Too much evaporation may induce oxidation and acid drainage in sub-aerially deposited tailings with sufficient acid-generating potential, and experience at several sites has shown that the exposure time before burial is a key parameter to minimise acid drainage onset (Al \& Blowes 1995; Bryan et al. 2010).

Analytical tools that could be helpful to assist designers in optimising rate of rise and lift thickness must incorporate a relatively realistic coupling between large strain consolidation and unsaturated flow. This is especially true in a cyclic deposition scheme, where fresh saturated tailings in a slurry state are placed on previously desiccated tailings. Particularly important is the hysteric behaviour of tailings in terms of volume change - tailings rewetted by rain or by burial by freshly placed tailings do not swell according to the same physics by which they were shrunk. This type of behaviour is often modelled in soils as an elasto-plastic phenomena. Therefore, for a cyclic deposition scheme where some desiccation is expected, analytical tools for deposition analysis should include both coupling between unsaturated flow and large strain consolidation, and account for elasto-plastic behaviour in both saturated and unsaturated states.

Fortunately, there are several existing theories that describe elasto-plastic behaviour in unsaturated soils, such as the state-surface model (SSM) (Zhang \& Lytton 2009) and the Glasgow coupled model (GCM) (Wheeler et al. 2003). The authors, who previously developed the UNSATCON code to couple unsaturated behaviour to large strain consolidation (Qi et al. 2016a, b), have implemented both these constitutive submodules (SSM and GCM) for simulating elasto-plastic behaviour during multilayer deposition (Qi et al. 2016c; Qi 2017). The large strain consolidation algorithm is modified from the piecewise linear approach of 
Fox and Bereles (1997) for unsaturated conditions, as described in Qi et al. (2016a). The model has been validated using field data from oil sands tailings (Qi et al. 2016b), through simulation of a multilayer drying box experiment of Daliri et al. (2016) for hard rock tailings, and from Rozina et al. (2015) for oil sands tailings - these simulations are reported in Qi et al. (2016c) and Qi (2017).

This paper shows examples of the calibration of material parameters and then hypothetical analysis applied to field deposition of two thickened tailings types: a fluid fine oil sands tailings (FFT) treated with a polymer, and a relatively coarse-ground gold tailings. These exploratory analyses are discussed in terms of relevance to field operations to maximise density and to minimise oxidation. The SSM formulation for hydromechanical coupling is employed in this paper.

\section{$2 \quad$ Materials and methods}

\section{$2.1 \quad$ Tailings characteristics}

\subsubsection{Gold tailings}

The gold tailings were obtained from an end of pipe sample from a gold mine in northern Ontario, Canada. The grain size curve (sieve and hydrometer), the $D_{10}, D_{50}$, and $D_{90}$ were 6,50 , and 150 microns respectively. Liquid and plastic limits (LL and PL) were 21.5 and 20 using the fall cone method. The specific gravity was 3.3. These tailings are slightly coarser than other gold tailings reported in the literature, particularly in terms of clay-size fraction. For example, Al-Tarhouni et al. (2011) reported gold with a $D_{10}<2$ microns, and a $D_{50}$ and $D_{90}$ of 35 and 150 microns respectively. Qiu and Sego (2001) reported $D_{10}, D_{50}$, and $D_{90}$ values of 1,45 , and 150 microns.

Unsaturated compressibility and water retention were measured using axis-translation tests with volume change measurement for suctions $<1 \mathrm{MPa}$, and measuring total suction using a dewpoint hygrometer for higher suctions (more details on these tests are reported in Simms et al. 2017). Data are shown in Figure 1.

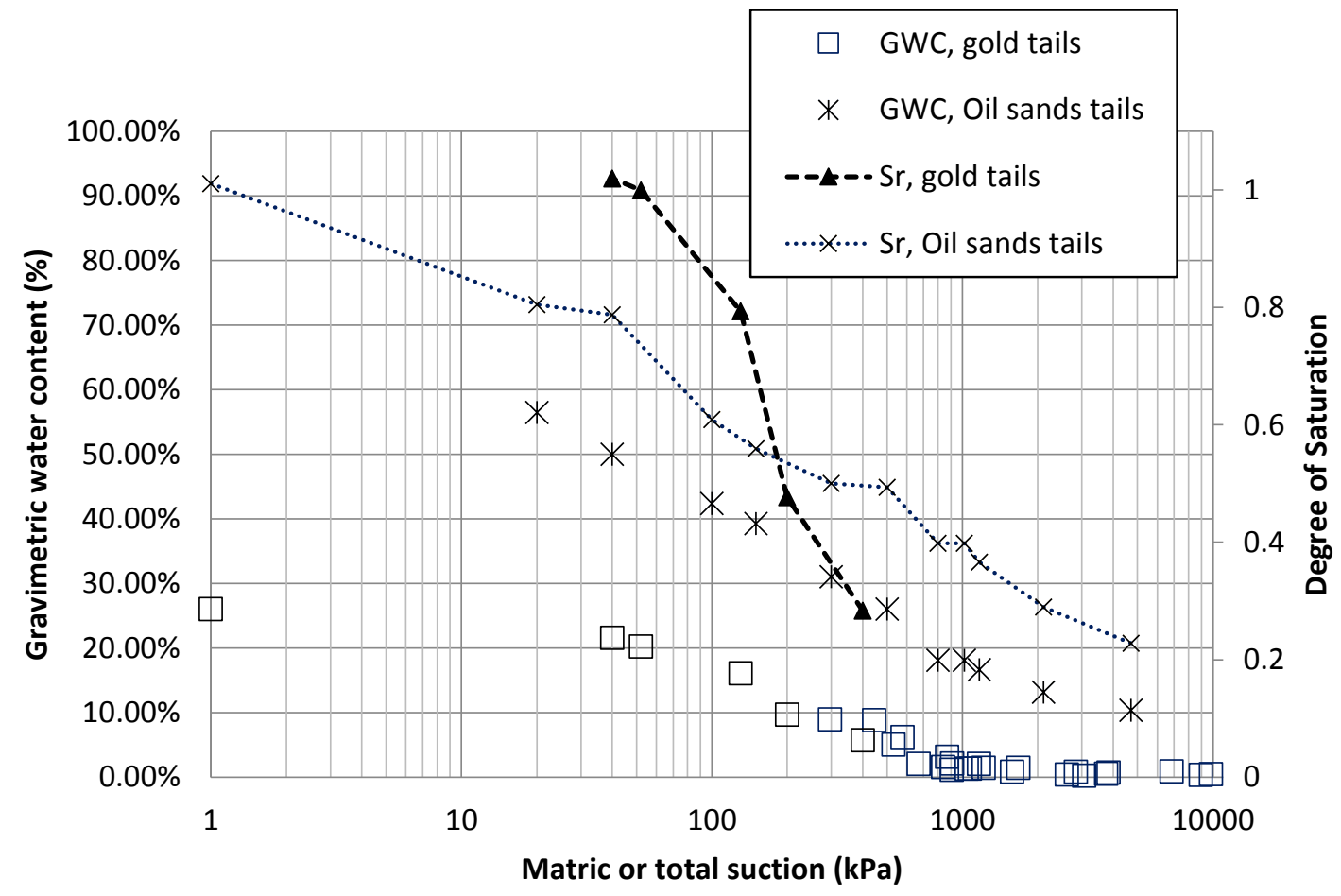

Figure 1 Water retention curves of gold and oils sands tailings used in the generic analyses; geotechnical gravimetric water content and degree of saturation 
Large strain consolidation characteristics were extracted from column tests with volumetric water contents (EC series probes from Decagon) and porewater pressure measurements (T5 tensiometers from UMS). Tests $0.50 \mathrm{~m}$ tall in $0.15 \mathrm{~m}$ diameter columns were performed at initial solids contents ranging from 65 to $70 \%$. Hydraulic conductivity was roughly estimated using fluxes and porewater pressures measured between pairs of porewater pressure sensors and water content sensors. The saturated hydraulic conductivity function was $5 \times 10^{-6} \times \mathrm{e}(\text { void ratio })^{4} \mathrm{~m} / \mathrm{s}$. The compressibility curve was determined from specific pairings of effective stress and void ratio measured in the column experiments. Large strain consolidation curves for both tailings are shown in Figures 2 and 3.

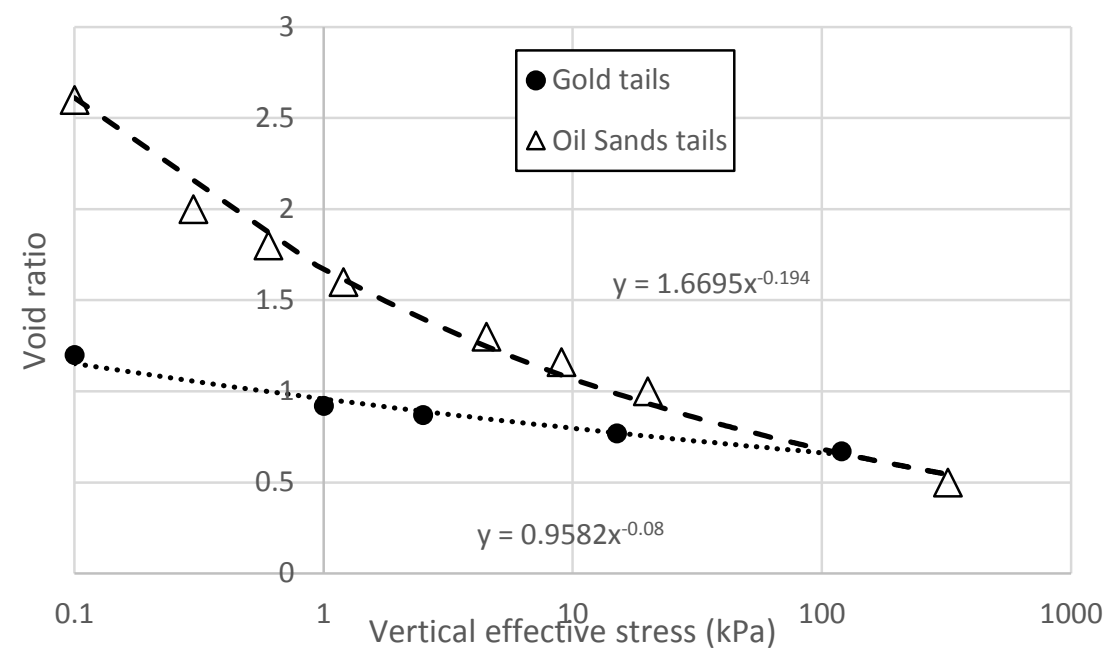

Figure 2 Saturated compressibility curves for the two tailings types

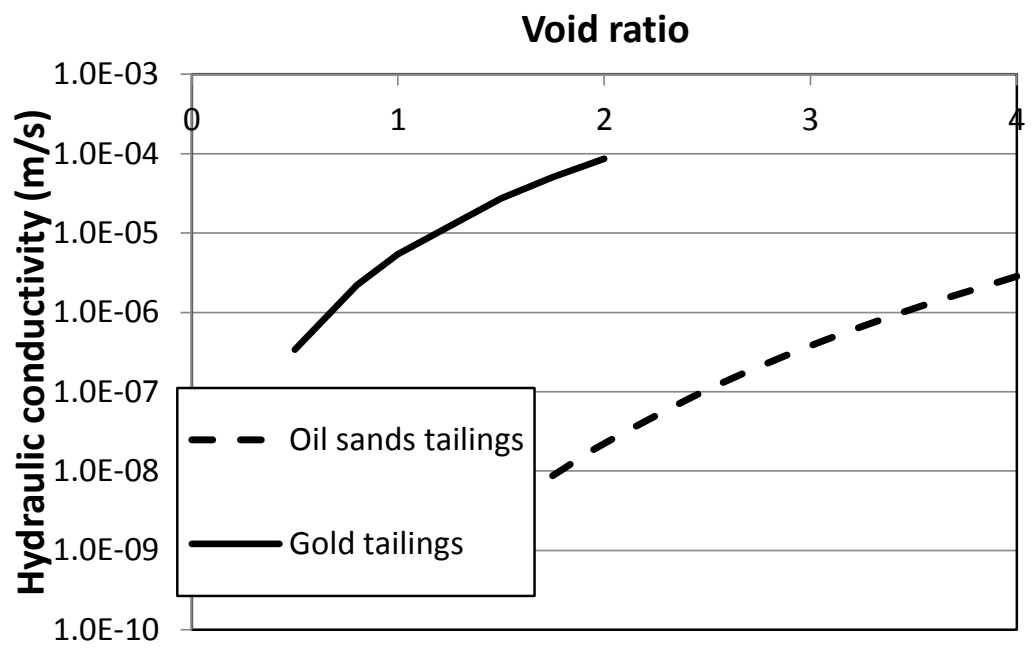

Figure 3 Saturated hydraulic conductivity functions for the two tailings

\subsubsection{Oil sands tailings}

These tailings are oil sands fluid fine tailings mixed with a particular polyacrylimide high molecular weight polymer at a particular dosage $(650 \mathrm{ppm})$. After preparation with the polymer, the grain size, $\mathrm{D}_{90}, \mathrm{D}_{50}$, and $D_{10}$ are 75,5 , and 0.8 microns respectively. The $L L$ and PL are 80 and 45 , both determined by the fall cone method. The specific gravity is 2.2 . The water retention curve and saturated compressibility data are given in Figures 2 and 3. The compressibility and saturated hydraulic data are the same as determined in Qi et al. (2017) from column tests where volumetric water content and pore-pressure measurements were used to infer fluxes and back-calculate corresponding hydraulic conductivity values. 


\section{$2.2 \quad$ Numerical model}

When using the SSM in UNSATCON, a three-dimensional plastic surface for void ratio, a moving elastic surface for void ratio, and a void ratio dependent water retention curve (WRC) are required to describe hydromechanical coupling, which enables calculation of water content (w), void ratio (e) in space and time as functions of total stress and matric suction/porewater pressure. The 3D plastic surface can be obtained by fitting the plastic surface equation to the saturated compressibility data and void ratio-matric suction data measured during the WRC. The plastic surface equation is adopted from Vu and Fredlund (2006):

$$
e=a+b \log \left[\frac{1+c \bar{\sigma}+d s}{1+f \bar{\sigma}+g s}\right]
$$

where:

$$
\begin{aligned}
e & =\text { void ratio. } \\
\sigma & =\text { the net normal total stress. } \\
S & =\text { matric suction. }
\end{aligned}
$$

As shown in Qi et al. (2016a), the 3D plastic surface is well-constrained by these two sets of data. The surface gives two S-shaped curves in either zero suction or zero stress space. The parameter $a$ is the intercept of the plastic surface and $b$ is the slope of a best-fit line through the saturated compressibility data (the virgin compression line). The shrinkage limit is equal to $a+b \log (d / g)$. The $c$ and $f$ parameters control the curvature of the surface near zero suction, or in other words, how the shape of the saturated compressibility curve deviates from a line in void ratio-log effective stress space. The moving elastic plane, which is analogous to the unload-reload line for saturated soils, requires slopes with respect to total stress $(\kappa)$ and matric suction $\left(\kappa_{s}\right)$. Any compression tests for similar tailings with an unload component and any rewetting data from a WRC test can be used to determine these values. Finally, the void ratio dependent WRC (anchor points $C_{d r y}$ and $C_{\text {wet }}$ for drying and wetting, $\lambda_{s r}$ slope of the WRC after the air entry value, $\kappa_{s s}$ slope of the WRC after the residual water content, $\lambda_{\text {se }}$ dependency of air entry value on void ration) requires WRC data at two separate void ratios. This can be done using an axis-translation device that permits application of a vertical load.

The permeability of tailings is given by the saturated hydraulic conductivity parameters $H_{1}$ and $H_{2}$, such that

\begin{tabular}{|c|c|c|c|c|c|c|c|c|}
\hline \multicolumn{9}{|c|}{ Volume change behaviour } \\
\hline Parameters & $A$ & $B$ & C & $D$ & $F$ & $G$ & $\kappa$ & $\kappa_{s}$ \\
\hline Value & 1.8 & 0.16 & 0.0031 & 0.023 & 223,000 & 327,000 & 0.015 & 0.0015 \\
\hline \multicolumn{9}{|c|}{ Water retention behaviour } \\
\hline Parameters & \multicolumn{2}{|c|}{ Cdrying } & $C_{\text {wetting }}$ & \multicolumn{2}{|l|}{$\lambda_{s e}$} & $\lambda_{s r}$ & \multicolumn{2}{|c|}{$\kappa_{s s}$} \\
\hline Value & \multicolumn{2}{|c|}{3.1} & 2.65 & \multicolumn{2}{|l|}{0.6} & 0.4 & \multicolumn{2}{|c|}{0.03} \\
\hline \multicolumn{9}{|c|}{ Hydraulic conductivity } \\
\hline \multicolumn{2}{|l|}{ Parameters } & \multicolumn{2}{|l|}{$H_{1}$} & \multicolumn{2}{|l|}{$\mathrm{H}_{2}$} & \multicolumn{3}{|c|}{$M$} \\
\hline \multicolumn{2}{|l|}{ Value } & \multicolumn{2}{|l|}{$5 \mathrm{E}-6$} & \multicolumn{2}{|l|}{4} & \multicolumn{3}{|c|}{0.75} \\
\hline
\end{tabular}
$\mathrm{k}_{\text {sat }}=\left(\mathrm{H}_{1} \times \mathrm{e}^{\mathrm{H} 2}\right)$, and a parameter $(M)$, accounts for the variation in permeability with degree of saturation.

Model parameters are listed in Tables 1 and 2 for the two tailings types.

Table 1 Model parameters for gold tailings 
Table 2 Model parameters for oil sands tailings

\begin{tabular}{|c|c|c|c|c|c|c|c|c|}
\hline \multicolumn{9}{|c|}{ Volume change behaviour } \\
\hline Parameters & $A$ & $B$ & C & $D$ & $F$ & G & $\kappa$ & $\kappa_{s}$ \\
\hline Value & 4.50 & $7.80 \mathrm{E}-01$ & $7.56 \mathrm{E}-03$ & $1.36 \mathrm{E}-01$ & $1.62 E+03$ & $2.17 E+03$ & 0.015 & 0.0015 \\
\hline \multicolumn{9}{|c|}{ Water retention behaviour } \\
\hline Parameters & $C_{d r y}$ & & $C_{\text {wetting }}$ & $\lambda_{s e}$ & & $\lambda_{s r}$ & & $\kappa_{s s}$ \\
\hline Value & 2.6 & & 2.5 & 0.4 & & 0.5 & & 0.04 \\
\hline \multicolumn{9}{|c|}{ Hydraulic conductivity } \\
\hline \multicolumn{2}{|l|}{ Parameters } & \multicolumn{2}{|l|}{$H_{1}$} & \multicolumn{2}{|l|}{$\mathrm{H}_{2}$} & \multicolumn{3}{|c|}{$M$} \\
\hline \multicolumn{2}{|l|}{ Value } & \multicolumn{2}{|c|}{$17.5 \mathrm{E}-11$} & \multicolumn{2}{|l|}{8} & \multicolumn{3}{|c|}{0.75} \\
\hline
\end{tabular}

Measurement requirements are more onerous than typically required by standard geotechnical investigations of tailings. However, one can calibrate some of the values from multilayer deposition tests at the bench scale, instrumented with volumetric water content and pore pressure matric suction tests. An example of such a test would be a drying box test (e.g. Daliri et al. 2016). Though a multilayer column test, along with a standard WRC test, and a saturated column test, are sufficient to provide the necessary parameters for the model.

One can visualise the constitutive surfaces as an extension of conventional saturated virgin compression and unload-reload lines into a 3D surface for dependency on suction (Figure 4). Details of the theory and operation of the UNSATCON code are given in the other sources (Qi et al. 2016a, 2016b, 2017; Qi 2017).

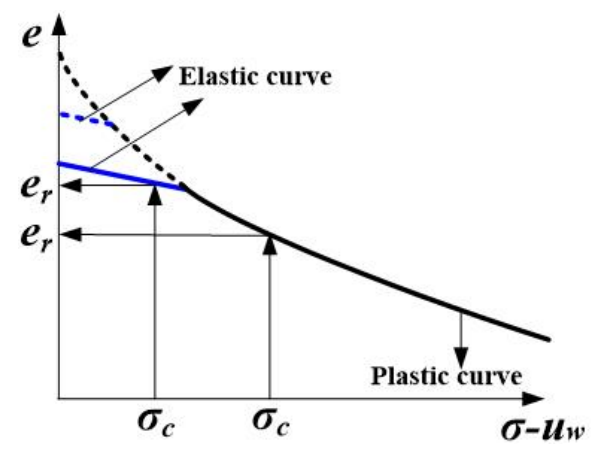

(a)

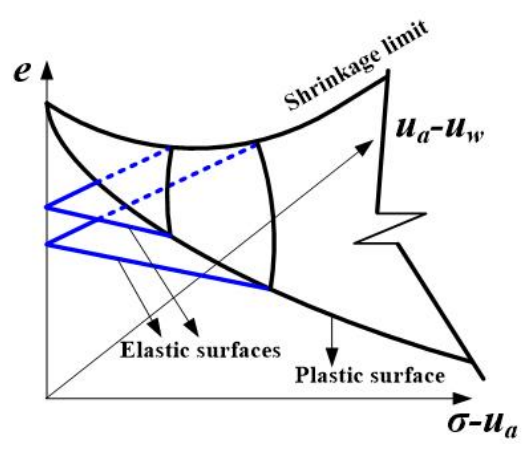

(b)

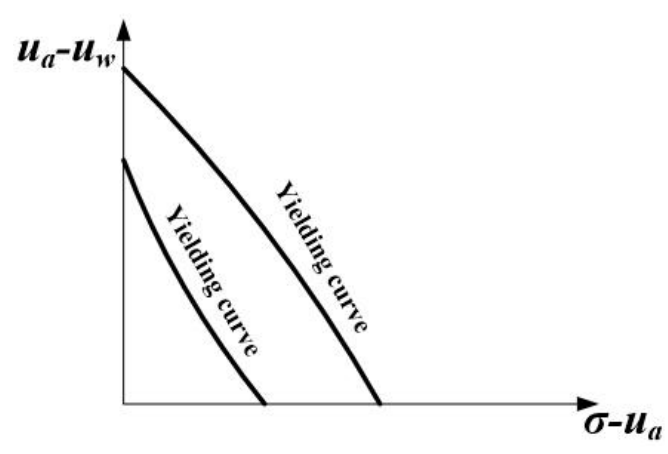

(c)

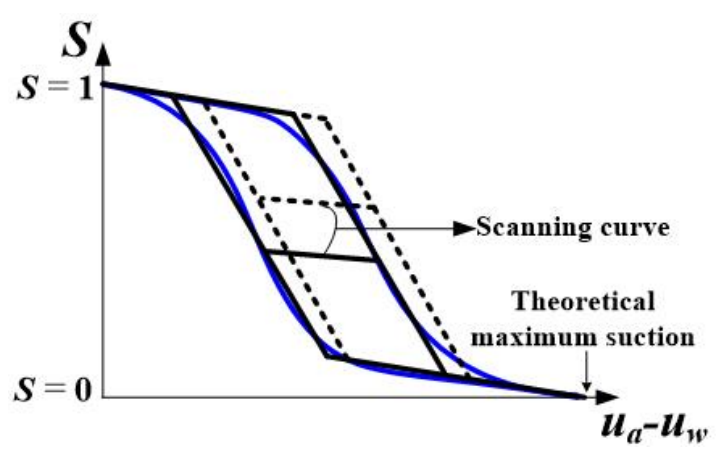

(d)

Figure 4 (a) Unsaturated constitutive surfaces compared to saturated conventional surface; (b) Elastic and plastic void ratio surfaces; (c) Yield curves for two different void ratios, which are the intersection of the elastic and plastic surface; and, (d) Void ratio dependent WRC 


\section{Generic field deposition analyses}

The hypothetical analyses for both tailings types are for an imaginary mine in a northern Canadian climate. A top boundary condition of $2 \mathrm{~mm} /$ day evaporation is applied during every summer (from 5 May to 1 October), and zero flux is applied during the remaining time with each year on the top surface of the fresh layer tailings. This boundary condition value is based on the assumption that precipitation will run off the tailings when they are still saturated. The top boundary condition was found to be suitable for analysing the performance of a field trial near Fort McMurray, Canada (Qi et al. 2017b). Note during the summer, desaturation can occur only when the evaporation rate is higher than the rate of water flowing to the top due to self-weight consolidation. When the rate of water flowing to the top due to self-weight is higher than the evaporation rate, the remaining water after consumption by evaporation is automatically removed by the model; excess bleed water is assumed to runoff. Zero flux is applied at the bottom of the tailings.

Different rates of rise, layer thickness (independent of rate of rise assuming multiple or varying deposition points), and two different deposition times (beginning of winter, the zero evaporation period, or the beginning of summer, the $2 \mathrm{~mm} /$ day evaporation rate period) were analysed.

\subsection{Oil sands tailings cases}

\subsubsection{Typical profiles predicted by the model}

Figures 5 and 6 show the profiles with depth of several parameters predicted by the model for two subsequent $1.2 \mathrm{~m}$ thick depositions of oil sands tailings. The first layer, deposited at the start of winter, shows a period of initial self-weight consolidation, characterised by lower void ratios and solids contents at the bottom of the tailings. After the start of summer, evaporation begins to reverse this profile, leading to a fairly uniform void ratio. The tailings substantially desaturate. After the addition of the second layer, part of the first layer near the bottom experiences some additional small plastic compression, though the top of the first layer remains on the unload-reload surface due to the larger amount of drying those tailings experienced before second layer deposition. Transport of water to resaturate the bottom layer accelerates the initial self-weight consolidation of the second layer. At the end of the second summer, only the very top of the bottom layer is somewhat desaturated.
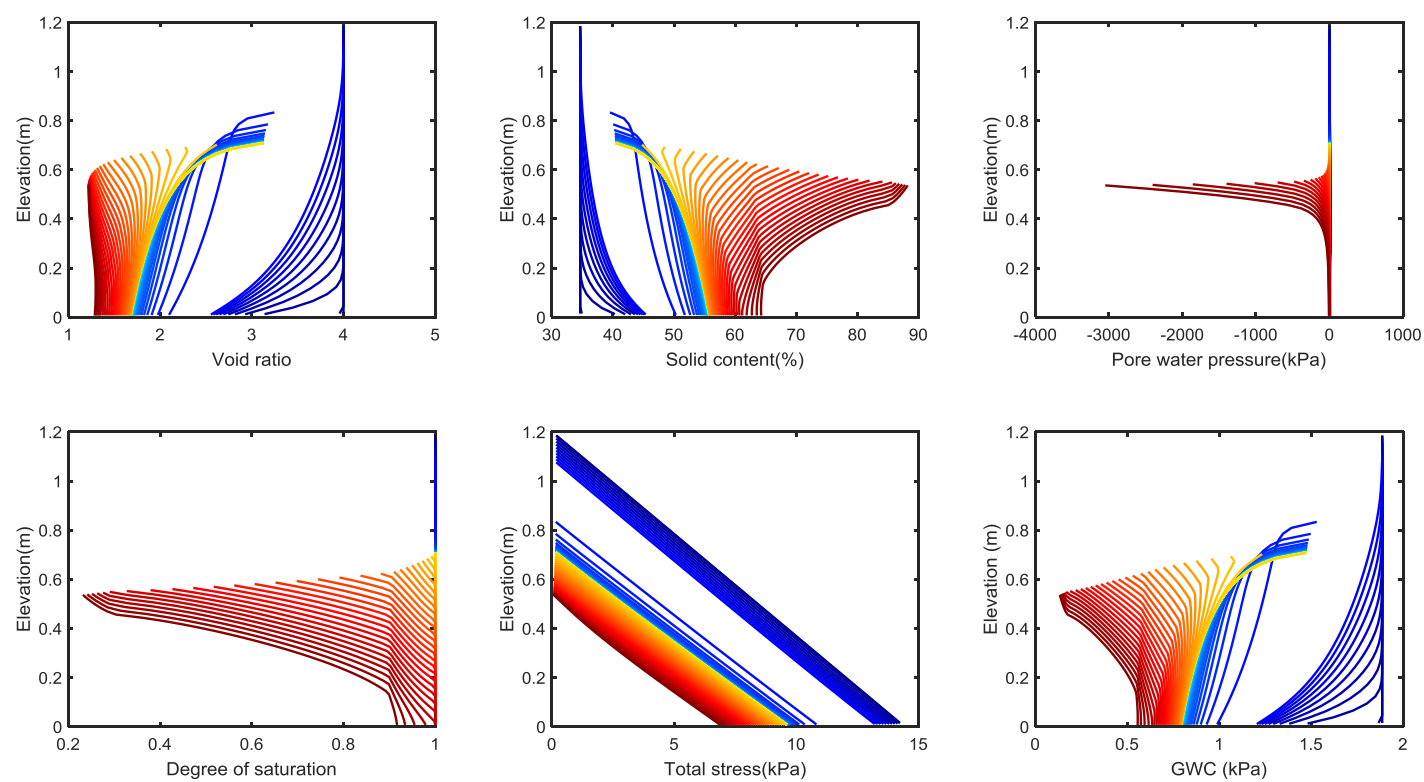

Figure 5 Depth profiles subsequent to deposition of the first layer, deposited start of winter. Profiles progress in time from blue to yellow to red to darker red 

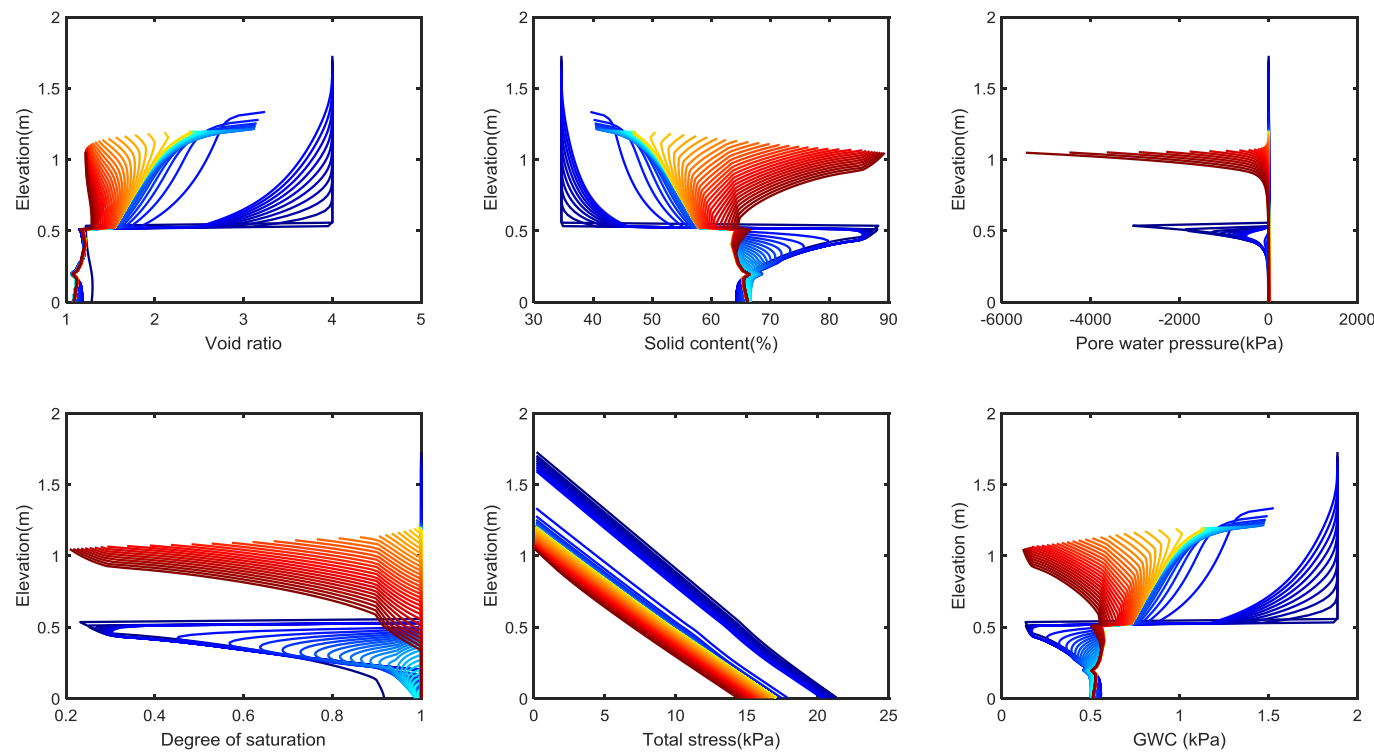

Figure 6 Depth profiles after deposition of second layer, start of following winter. Profiles progress in time from blue to yellow to red to darker red

\subsubsection{Winter versus summer deposition}

For the oil sands tailings, winter deposition results in more dewatering compared to summer deposition. During summer deposition, the evaporative boundary condition is partially satisfied by the flow of bleed water to the surface. Therefore, evaporation is more effective at dewatering once self-weight consolidation and the associated expression of water on the surface has stopped. An example of the overall water content for a single layer deposition of $2.4 \mathrm{~m}$ is shown in Figure 7.

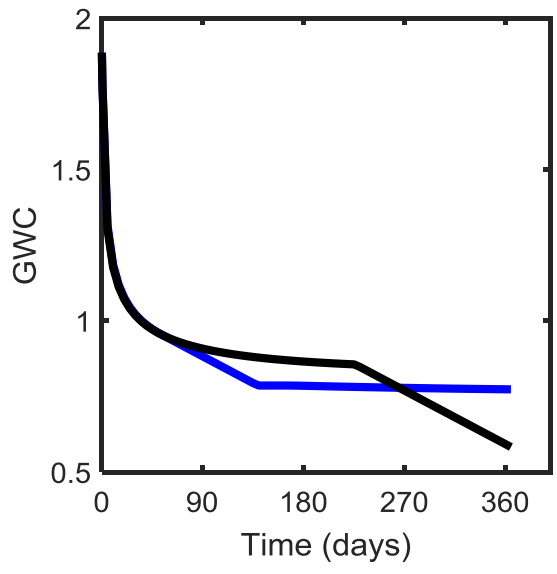

(a)

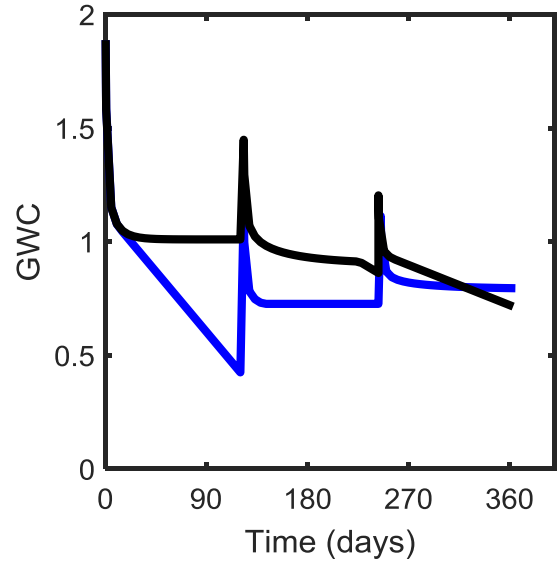

(b)

Figure 7 Average gravimetric water content for summer deposition (blue) and winter deposition (black); (a) A single layer $1.2 \mathrm{~m}$ thick; and, (b) Three layers of $0.4 \mathrm{~m}$

For this same case, there appears to be no advantage in increasing the frequency of layer deposition for this rate of rise. Figure $7(\mathrm{~b})$ shows the average water content of tailings, deposited in three lifts of $0.4 \mathrm{~m}$. The final water content at the end of the year is higher (70\%) compared to the water content of the single layer deposit (55\%). This is again because of the competition between bleed water release and evaporation. 


\subsubsection{Optimal rate of rise for yearly deposition}

The results shown in Figure 8 are generated assuming yearly winter deposition, with varying rates of rise. For the tailings and the assumed simple climate, there appears to be an optimal rate of rise of about $1 \mathrm{~m}$ per year. Higher rates of rise generate tailings with higher average ratios, and profiles with much more variability in density. Evaporation no longer influences the full depth of the tailings layer. Rates of rise less than $1 \mathrm{~m}$ per year lead to interference between contributions from dewatering from consolidation and evaporation. Note the jagged void ratio profiles are real and not numerical noise. These are due to the influence of small plastic compression in part of the underlying tailings by increases in total stress each time a new layer is added. This is shown in the example depth profiles earlier in the paper (Figures 5 and 6 ).

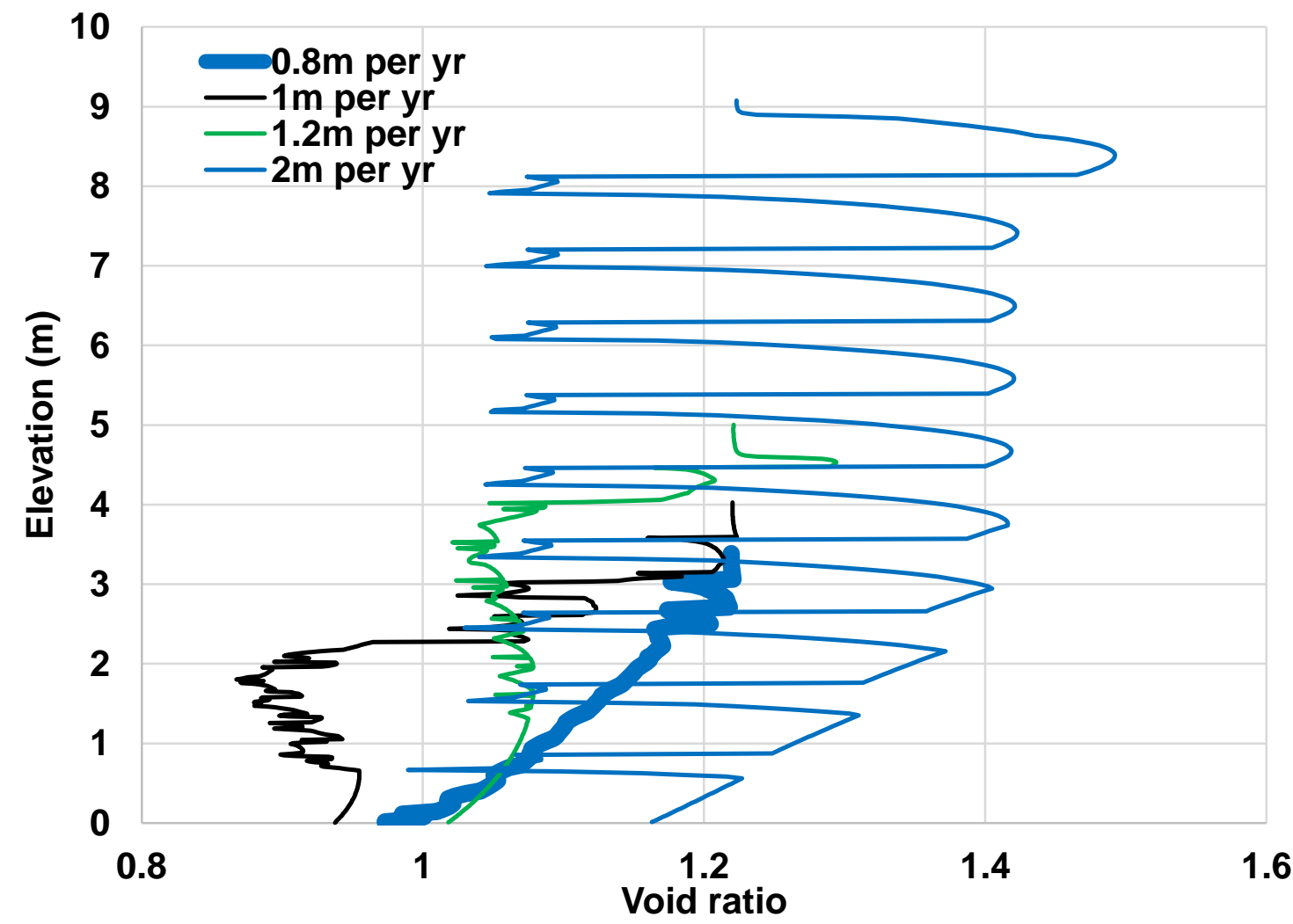

Figure 8 Different rates of rise, yearly winter deposition

Of interest to oil sands operations is a comparison between layered deposition and continuous filling. The latter is possible as there are existing reservoirs of fluid fine tailings that must be converted into reclaimable deposits. One option is to process these stored tailings relatively quickly to generate deep, thick deposits. These instantaneous large deposits are compared with yearly deposition in Figure 9 for two rates of rise. It can be seen that there is a substantial improvement in the profile (void ratio reduced to 0.9 in the lower half of the impoundment) for the yearly deposition of $1 \mathrm{~m}$ per year, but much less so for the $1.5 \mathrm{~m}$ rate of rise (void ratio for both continuous filling and layered deposition are similar and give average void ratios of 1.1 and 1.25 for layered and continuous filling, respectively). 

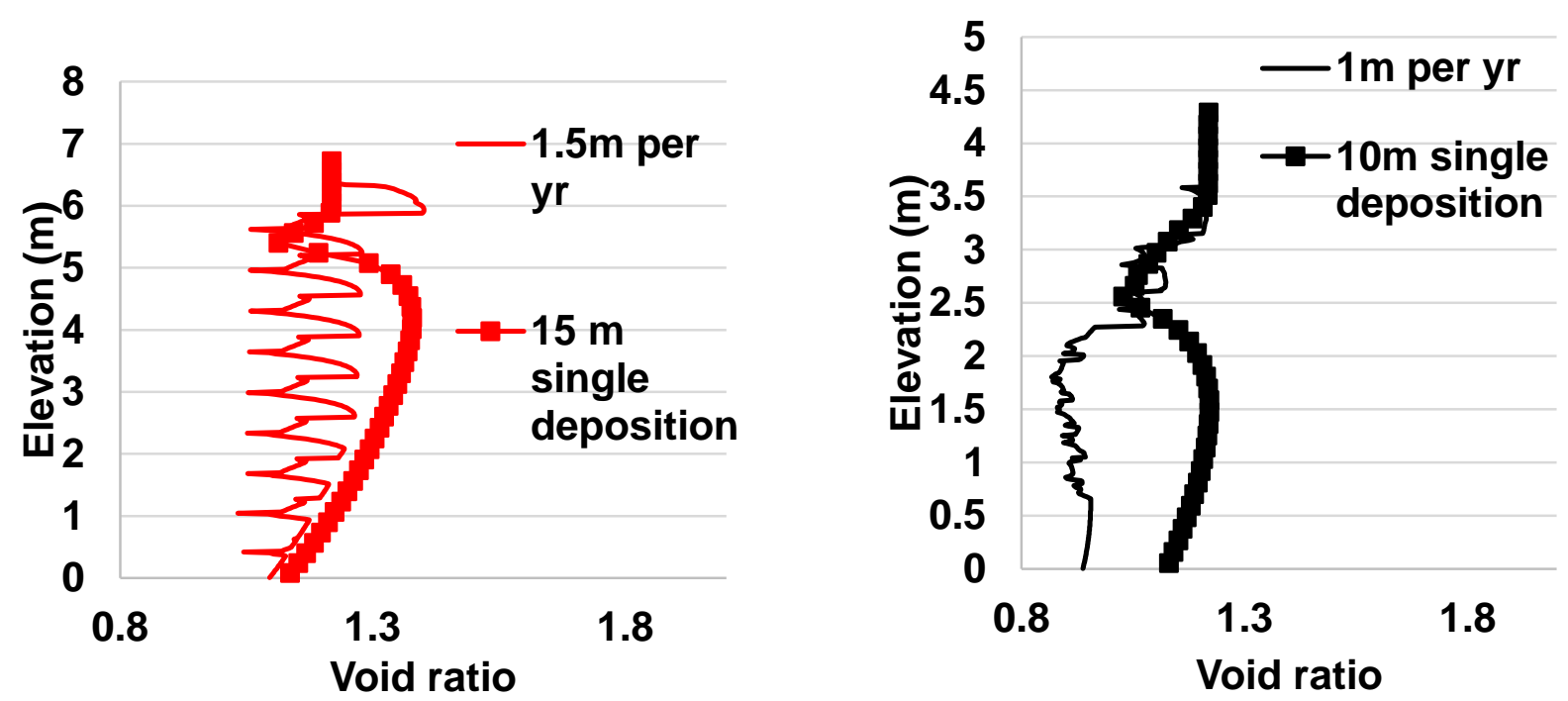

Figure 9 Yearly deposition compared with single deep deposit for two rates of raise

Operators should consider that in deep deposits, thixotropy has been shown to impede strength gain and may retard dewatering below what is projected by large strain consolidation analysis for both unamended fluid fine tailings (Jeerivapoolvarn et al. 2009), and for polymer amended FFT (Salam et al. 2017). Additionally, operators run somewhat of a gamble when creating a large deposit of treated and/or dewatered FFT, as the expected dewatering behaviours of the deposited tailings may shift with unexpected changes in the orebody, the bitumen extraction process, and tailings processing. Gradual or layered deposition may be better from a risk management perspective.

\subsection{Gold tailings}

The gold tailings are much different in their consolidation behaviour, and therefore the influence of rate of rise, layering, and deposition time is quite different than for the oil sands tailings. Cases presented include summer and winter deposition for single layer deposits from 1 to $3 \mathrm{~m}$, and for biannual deposits for the same rates of rise.

The relatively high hydraulic conductivity results in more uniform profiles of void ratio and other parameters with depth. Figure 10 shows profiles after three years for different rates of rise for annual layer deposition. The void ratios resulting from the different deposition schemes do not change very much. Self-weight consolidation for all cases happens over a matter of days, and even for the $3 \mathrm{~m}$ rate of rise case, the evaporation rate is more than sufficient to bring the tailings to their shrinkage limit ( $20 \%)$ from the post-consolidation water content $(\sim 24 \%)$. Therefore, the void ratio's small variability with depth is due to the variation in total stress as the tailings accumulate. The water content profiles and the degree of saturation profiles do vary with rate of rise, as proportionally more water is removed following self-weight consolidation for the slower rates of rise. 

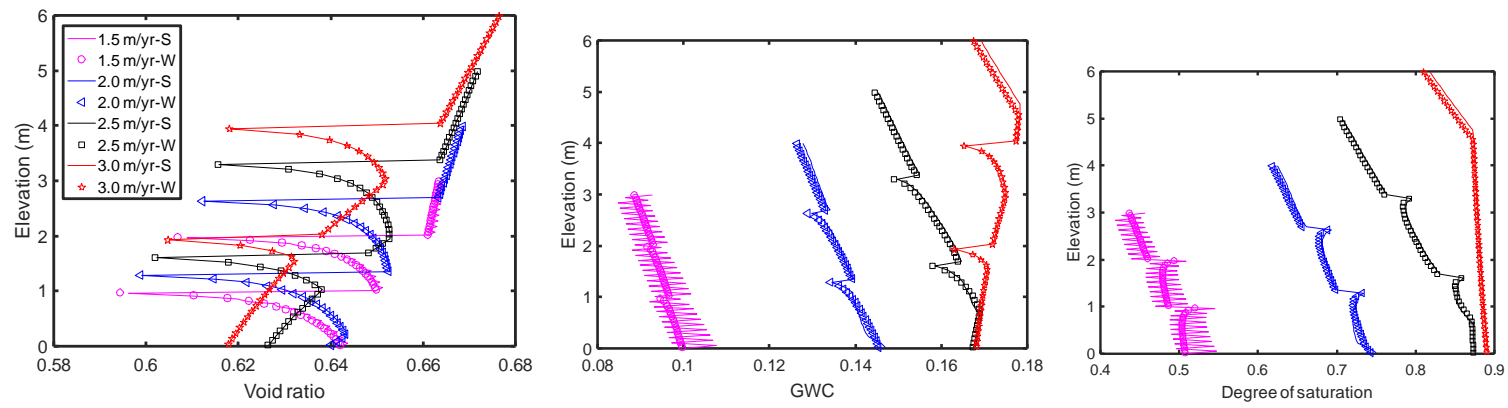

Figure 10 Depth profiles for gold tailings for different rates of rise for yearly deposition, summer or winter, after three years

In Figures 10 and 11, which show the average void ratio of the deposit for all deposition schemes, it can be seen that void ratio development is independent of whether deposition is done in winter or summer. Again, this is because self-weight consolidation occurs so rapidly there is no evaporative potential lost because of the bleed water, following the model assumption that excess bleed water runs off the tailings. The void ratio trends after self-weight consolidation for winter or summer deposition conform to field measurements in wet or dry seasons reported at some sites in a similar climate (Kam et al. 2014; Simms 2016).

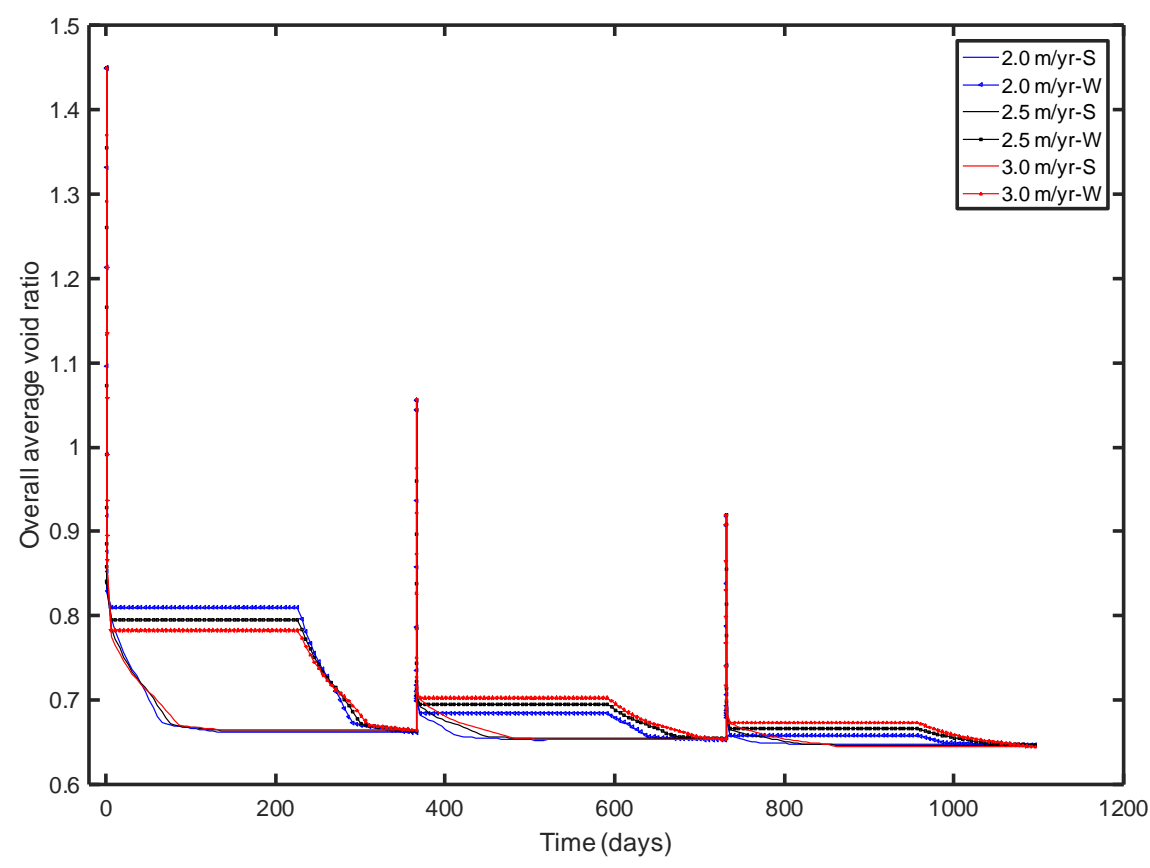

Figure 11 Average void ratio for whole deposit for different rates of rise, yearly deposition

However, deposition timing does have an influence on the average degree of saturation, and therefore the risk of acid generation, for those tailings which are susceptible to oxidation and have limited neutralising potential. The amount of tailings exposed to oxidation is quantified in Figure 12 by multiplying the depth of the deposit by the average degree of saturation. The risk of acid generation increases with exposure time where tailings are below a degree of saturation of about $90 \%$. Figure 12 therefore shows that depositing at the start of winter will limit the exposure time of tailings to oxidation, as the time where the degree of saturation drops below 1 is less. The difference between winter and summer deposition in terms of risk of acid generation would in reality be somewhat less, as some of the tailings would become desaturated during winter, and low winter temperatures reduce the rate of oxidation. Figure 12 also illustrates how increasing the frequency of layer deposition can be used to reduce oxygen exposure time for tailings - the additional of a new layer will desaturate the underlying tailings with bleed water from the new layer. Therefore, varying deposition time and increasing deposition frequency do have value for managing the risk of acid generation for hard rock tailings. 


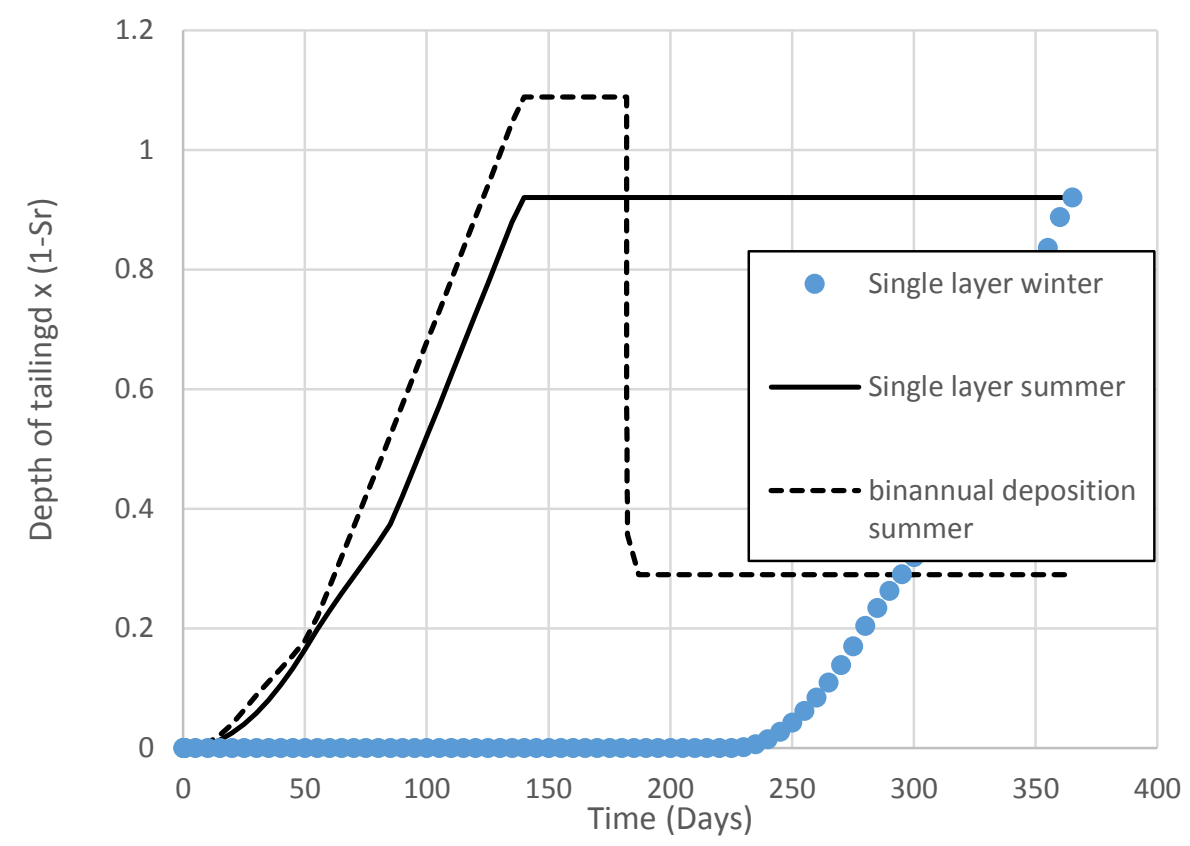

Figure 12 Influence of deposition timing and deposition frequency on desaturation

\section{Conclusion}

The multilayer deposition analyses suggest different optimal deposition timing and frequency depending on deposit performance objectives and tailings types.

For the oil sands fine tailings case:

- An optimal rate of rise could be found for the specific climate analysed for maximising density. An optimal rate of rise maximises the contributions of self-weight consolidation and drying to volume change.

- In a yearly deposition scheme, deposition at the start of winter appears preferable to deposition at the start of summer, due to the evaporative potential being partially satisfied by bleed water for summer deposition.

- Layered deposition outperformed large single deposits for certain rates of rise. Other considerations, such as thixotropy, need to be considered for assessing the performance of deep deposits.

For the gold tailings case:

- Densification was insensitive to a large range of rate of rise as well as deposition timing due to the relatively fast self-weight consolidation of these tailings.

- Exposure time of desaturated tailings, which is a risk factor for acid drainage formation, was affected by deposition timing and layer frequency. Deposition at the start of winter, or increasing the number of layers for a given rate of rise, could decrease exposure time.

Winter versus summer deposition is probably not a real option for most operations outside of the oil sands industry (where existing FFT deposits must be reprocessed), as tailings must be deposited as they are created. However, decreasing the cycle time between deposition points in summer is a potential strategy for reducing the risk of aid generation.

These findings strictly apply to the hypothetical analysis considered. Site-specific analyses are recommended for real projects, and such analyses can aid but not replace engineering judgement and experience in selecting an appropriate tailings deposition plan. 


\section{Acknowledgement}

The development of the UNSATCON software was funded by Canada's Oil Sands Innovation Alliance (COSIA) and the Natural Science and Engineering Research Council of Canada (NSERC).

\section{References}

Al, TA \& Blowes, DW 1995, A Geochemical, Hydrogeological and Hydrological Study of the Tailings Impoundment at the Falconbridge Limited, Kidd Creek Division Metallurgical Site, Timmins, Ontario, Mend Report 2.23.2d, viewed 15 February 2018, http://mend-nedem.org/wp-content/uploads/2232D.pdf

Al-Tarhouni, M, Simms, P \& Sivathayalan, S 2011, 'Cyclic behaviour of reconstituted and desiccated samples of thickened gold mine tailings', Canadian Geotechnical Journal, vol. 48, no. 7, pp. 1044-1060.

Bryan, R Simms, P \& Verburg, R 2010, 'Coupling oxidation to transient drying in surface deposition of thickened tailings', Minerals Engineering, vol. 23 pp. 1101-1112.

Daliri, F, Simms, P \& Sivathayalan, S 2016, 'Shear and dewatering behaviour of high density gold tailings in a laboratory simulation of multi-layer deposition', Canadian Geotechnical Journal, vol. 53, pp. 1246-1257.

Daliri, F, Kim, H, Simms, P \& Sivathayalan, S 2014, 'Impact of desiccation on monotonic and cyclic shear strength of thickened gold tailings', Journal of Geotechnical and Geoenvironmental Engineering, vol. 140, no. 9, pp. 04014048-1-04014048-13.

Fox, PJ \& Berles, JD 1997, 'CS2: A piecewise-linear model for large strain consolidation', International Journal for Numerical and Analytical Methods in Geomechanics, vol. 27, pp. 453-475.

Jeeravipoolvarn, S, Scott, JD \& Chalaturnyk, RJ 2009, ' $10 \mathrm{~m}$ standpipe tests on oil sands tailings: Long-term experimental results and prediction', Canadian Geotechnical Journal, vol. 46, no. 8, pp. 875-885.

Kam, S, Girard, J, Hmidi, N, Mao, Y \& Longo, S 2011, 'Thickened tailings disposal at Musselwhite Mine', in RJ Jewell and AB Fourie (eds), Proceedings of the 14th International Seminar on Paste and Thickened Tailings, Australian Centre for Geomechanics, Perth, pp. 225-236.

Qi, S 2017, Numerical Investigation on Slope Stability of Expansive soils and Large Strain Consolidation of Soft Soils, PhD dissertation, University of Ottawa/Ottawa-Carleton Institute for Graduate studies in Civil Engineering, Ottawa, $520 \mathrm{p}$.

Qi, S, Simms, P \& Vanapalli, S 2016a, 'Piecewise-linear formulation of coupled large strain consolidation and unsaturated flow. I: model development and implementation', Journal of Geotechnical and Geoenvironmental Engineering, vol. 143, no. 7, http://dx.doi.org/10.1061/(ASCE)GT.1943-5606.0001657

Qi, S, Simms, P, Vanapalli, S \& Soleimani, S 2016b, 'Piecewise-linear formulation of coupled large strain consolidation and unsaturated flow. II model calibration and testing', ASCE Journal of Geotechnical and Geoenvironmental Engineering. http://dx.doi.org/10.1061/(ASCE)GT.1943-5606.0001658

Qi, S, Daliri, F Simms, P \& Vanapalli, S 2016c, 'A large strain consolidation-unsaturated flow model for tailings analysis: multilayers', Proceedings of the 69th Canadian Geotechnical Conference.

Qi, S, Salam, M \& Simms, P 2017, 'Modelling thixotropy at short and long time scales in dewatering analyses for soft soil or tailings', Proceedings the 70th Canadian Geotechnical Conference.

Qiu, Y \& Sego, DC 2001, 'Laboratory properties of mine tailings', Canadian Geotechnical Journal, vol. 38, pp. $183-190$.

Rozina, E, Mizani, S, Malek, M, Sanchez-Sardon, M \& Simms, P 2015, 'Dewatering in a laboratory simulation of a multilayer deposit of inline flocculated mature fine tailings', in RJ Jewell and AB Fourie (eds), Proceedings of the 18th International Conference on Paste and Thickened Tailings, Australian Centre for Geomechanics, Perth, pp. 81-93.

Salam, M, Simms, P \& Ormeci, B 2017, 'Investigation of creep in polymer amended oil sands tailings', Proceedings of the 70th Canadian Geotechnical Conference.

Simms, P 2016, '2013 Colloquium of the Canadian Geotechnical Society: Geotechnical and geoenvironmental behaviour of high-density tailings', Canadian Geotechnical Journal, vol. 54, no. 4, pp. 455-468.

Simms, P, Soleimani, S, Mizani, S, Daliri, F, Dunmola, A, Rozina, E \& Innocent-Bernard, T 2017, 'Cracking, salinity and evaporation in mesoscale drying experiments on three types of tailings', Environmental Geotechnics, https://doi.org/10.1680 /jenge.16.00026

Vu, HQ \& Fredlund, DG 2006, 'Challenges to modelling heave in expansive soils', Canadian Geotechnical Journal, vol. 43, pp. 1249-1272.

Wheeler, SJ, Sharma, RS \& Buisson, MSR 2003, 'Coupling of hydraulic hysteresis and stress-strain behaviour in unsaturated soils', Géotechnique, vol. 53, pp. 41-54.

Zhang, X \& Lytton, RL 2009, 'Modified state-surface approach to the study of unsaturated soil behavior. Part I: basic concept', Canadian Geotechnical Journal, vol. 46, pp. 536-552. 